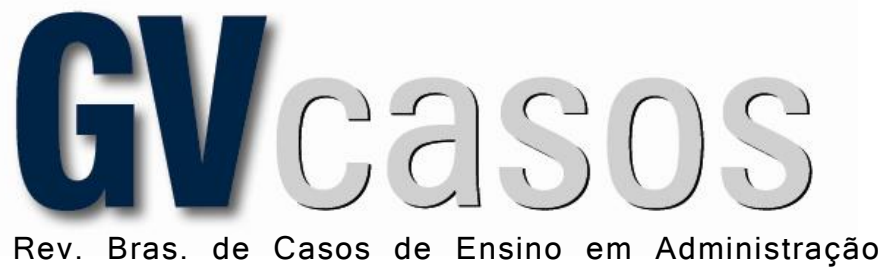

DOI: http://dx.doi.org/10.12660/gvcasosv11n1c7

\title{
FATURAMENTO ESTAGNADO E BAIXA RENTABILIDADE. E AGORA, COMO A SUPERA VAI VIRAR O JOGO?
}

Stagnated billing and low profitability. And now, how will Supera turn the game?

AleXSANDER CANAPARRo - canaparro.mba@gmail.com

Universidade do Vale do Rio dos Sinos - Porto Alegre, RS, Brasil

KADÍGIA FACCIN - kadigiaf@unisinos.br

Universidade do Vale do Rio dos Sinos - Porto Alegre, RS, Brasil

DiEgo MarConatTo - $\underline{\text { dmarconatto@ unisinos.br }}$

Universidade do Vale do Rio dos Sinos - Porto Alegre, RS, Brasil

Submissão: 29/12/2020 | Aprovação: 01/02/2021

\section{Resumo}

Este caso é uma narrativa com enredo fictício, baseado em fatos reais vivenciados pelo autor ao longo da sua trajetória profissional. Para tanto, apresenta-se a Supera, líder nacional no segmento de utilidades domésticas no Brasil. Uma empresa com 47 anos de existência, que viveu boa parte da sua história em um contexto de crescimento acelerado e domínio do mercado. Entretanto, nos últimos cinco anos, as coisas não andam muito bem - reflexo das escolhas estratégicas da empresa. A Supera mudou radicalmente a sua estratégia de go to market (GTM) e pagou um preço alto por isso. Agora, precisa encontrar novos caminhos estratégicos para reverter essa situação.

Palavras-chave: negociação, estratégia, processo decisório, gestão.

\begin{abstract}
This case is a narrative with a fictional plot, based on real facts experienced by the author throughout his professional career. To this end, Supera is introduced, a national leader in the domestic utilities segment in Brazil. A company with 47 years of existence, which has lived a good part of its history in a context of accelerated growth and market dominance. However, in the past five years, things have not been going very well - reflecting the company's strategic choices. Supera has radically changed its go to market (GTM) strategy and paid a high price for it. Now, it need to find new strategic ways to reverse this situation.
\end{abstract}

Keywords: negotiation, strategy, decision making, management.

\section{Introdução}

Em uma noite fria e chuvosa, característica do inverno gaúcho, João da Silva se prepara para finalizar mais um dia de trabalho na empresa onde atua como Diretor Comercial. A Supera é líder nacional no segmento de utilidades domésticas no Brasil e está no mercado há mais de 47 anos. Entretanto, a empresa está passando por um momento delicado e bastante desafiador, reflexo das decisões estratégicas tomadas pelo seu antecessor. João tinha iniciado o novo desafio três meses atrás. A sua contratação precedeu uma longa negociação, dado o tamanho do desafio que se apresentava. Entre as condições colocadas por João, três eram centrais: (1) prazo de três meses para elaboração de um diagnóstico detalhado do negócio; (2) prazo de 12 meses para execução do 
planejamento estratégico, após validação e; (3) liberdade para estruturar as áreas comercial, marketing e produto - que estavam sob a responsabilidade da diretoria.

Depois de um dia longo de trabalho, João queria somente ir para casa e descansar, pois no outro dia teria que chegar cedo na empresa. Ao chegar ao estacionamento, assim que entra no carro, recebe uma ligação do seu superior - a notícia não era boa. Após 30 minutos de conversa com Facundo de Albuquerque, CEO da empresa, João consegue finalmente seguir para casa. O caminho é longo, algo em torno de uma hora de deslocamento - tempo importante para reflexão sobre o que havia conversado ao telefone minutos atrás. João é um profissional experiente, com mais de 20 anos de mercado, com vivência no exterior e atuação em grandes empresas - nacionais e multinacionais. Mas, desta vez, seguramente a primeira, ele não sabia qual caminho seguir. Até João receber a ligação do CEO, tudo corria conforme combinado. Já haviam se passado três meses, e João estava muito satisfeito com a sua decisão em aceitar a proposta da empresa.

Entretanto, após a ligação do CEO, João teve que acelerar o desenvolvimento e execução do planejamento estratégico, pois o contexto impôs uma ação imediata, conforme Albuquerque relatou ao telefone:

- João, o Conselho de Administração está me pressionado em relação aos resultados financeiros deste ano. Além disso, nos últimos cinco anos, nosso faturamento praticamente estagnou - paramos de crescer. Temos que atacar os principais ofensores do nosso resultado. Você precisa apresentar um plano em 30 dias, no máximo - que deverá contemplar ações que resultem em reversão desse cenário em seis meses, pois nossos empregos estão em jogo.

Depois dessa ligação, João passou a noite pensando: "O que eu vou fazer para reverter essa situação?".

\section{A empresa}

A Supera iniciou suas atividades em 1973, em Porto Alegre, no estado do Rio Grande do Sul. Sua trajetória iniciou com a chegada ao Brasil dos seus dois sócios e irmãos - Manoel e Joaquim, nascidos em Portugal, na cidade do Porto. Os dois saíram de seu país com o objetivo de abrir um negócio na "terra de oportunidades" - assim como era conhecido o Brasil, segundo o seu velho avô contava nos muitos almoços em família. Nessa época, o Brasil vivia um clima de euforia econômica, o chamado "milagre econômico brasileiro" - com altas taxas de crescimento do PIB nos anos de 1969 a 1973.

Manoel e Joaquim Supera chegaram ao Brasil, especificamente, em Porto Alegre, em novembro de 1972. Eles não foram os primeiros da família Supera a tomar essa decisão. Vinte anos antes, o irmão do seu pai já havia aberto esse caminho. O Tio Pereira morava no Brasil havia mais de 20 anos e, praticamente por esse mesmo período, tinha uma pequena fábrica de utensílios domésticos na cidade. Muito cansado e acometido por uma doença grave, o Tio Pereira não tinha mais condições de tocar a empresa. A chegada dos sobrinhos serviu de alento ao Tio Pereira - uma vez que ele vinha postergando a decisão de fazer um longo tratamento médico, pois estava tentando vender a fábrica e não encontrava comprador.

Nesse contexto, os irmãos Supera viram-se diante de uma oportunidade - duas, na verdade: ajudar o tio, que precisava tratar sua doença, e, ao mesmo tempo, abrir o seu próprio negócio. Foi então que fizeram a proposta de comprar a fábrica. Não tinham todo o montante suficiente, mas, como o negócio era em família, tudo se acertou. Propuseram ao Tio Pereira $50 \%$ de entrada e o restante parcelado em 36 meses. Fechado o negócio, dois meses depois da chegada dos irmãos ao Brasil, em janeiro de 1973, nascia a "nova" fábrica de utensílios domésticos - pois a primeira decisão dos novos donos, dado o contexto, foi mudar o nome da empresa para Supera Utilidades para o Lar. 
Os primeiros anos foram muito difíceis, pois os irmãos não entendiam do negócio. Em função do seu problema de saúde, o Tio Pereira conseguiu acompanhá-los somente nos primeiros seis meses. Mas a força e a determinação foram essenciais para superar todos os obstáculos que se apresentavam. Nos primeiros três anos, praticamente todo o lucro foi destinado ao pagamento das 36 parcelas restantes, conforme acordado com o Tio Pereira. Passado esse período, os irmãos Supera já se sentiam seguros em ampliar os negócios da empresa. Traçaram um plano arrojado de atualização do parque fabril (maquinário e tecnologia) para os próximos quatro anos (1977/1980) - sempre mantendo o foco total na estratégia de diferenciação da empresa, ou seja, a qualidade dos produtos e o design, algo de que o Tio Pereira nunca abriu mão.

Seguindo essa esteira, nas três décadas seguintes, a Supera vivenciou uma trajetória de sucesso amparada por uma estratégia de crescimento sustentada em quatro pilares: (1) ampliação do portfólio; (2) ampliação geográfica; (3) estruturação comercial e; (4) canais de distribuição (Anexo $1)$.

Nos anos 1980, a empresa focou a ampliação do portfólio de produtos. Com a atualização do parque fabril e o desenvolvimento de novas tecnologias, novas oportunidades de desenvolvimento de produtos foram surgindo ao longo dos anos. Esse foi um período importante para a Supera, pois a empresa ganhou vários prêmios nacionais e internacionais de design e funcionalidade.

Os anos 1990 ficaram marcados como o período em que a empresa se consolidou no marcado nacional, levando seus produtos aos supermercados em todos estados do Brasil. A Supera ampliou a sua área geográfica de atuação, pois a empresa atuava somente nas regiões Sul (Rio Grande do Sul, Santa Catarina e Paraná) e Sudeste (São Paulo e Rio de Janeiro) do Brasil. Também ficou marcado como início das exportações para os países da América Latina.

Nos anos 2000, no mercado interno, a empresa implantou um audacioso projeto de estruturação comercial em nível nacional - com abertura de quatro regionais de vendas distribuídas nos principais estados brasileiros. Essa estratégia fez parte de um processo de governança/profissionalização da empresa, que contemplou, entre outras coisas, a contratação de um CEO em 2005 - com isso, Joaquim e Manoel passaram a compor o Conselho de Administração da empresa.

Nesse contexto, a partir de 2010, o desafio da Supera foi buscar novos canais de distribuição, uma vez que, até então, a empresa comercializava seus produtos exclusivamente em redes de supermercados - um dos primeiros movimentos foi a contratação de um Diretor Comercial nesse mesmo ano. A partir disso, eis que, em 2011, a empresa começou a vender no canal atacadista e, um ano depois, em 2012, fez uma parceria com o maior atacadista do Brasil - Atacado Mineirão.

Passado esse período, após quase cinco décadas, a Supera faturou R $\$ 322$ milhões no ano de 2015, atendendo todo o território nacional. Além disso, está presente nos principais países das Américas Latina e Central. A empresa conta com cerca de 1.500 colaboradores e localiza-se em uma sede própria, instalada em um espaço de 80 mil metros quadrados de área. A linha de produção conta com produtos de alta qualidade, destinados a atender três diferentes segmentos: escritório, casa e lazer.

Desde o início das suas operações, a empresa se mantém presente nas prateleiras dos principais supermercados do Brasil. Além disso, a Supera é reconhecida e destaca-se pelo pioneirismo em patentes e registros de projetos no segmento de utilidades domésticas. A empresa é conhecida por criar produtos "ícones", que conseguem se perpetuar através das gerações - como é o caso do Superamax, lançado em 1983.

\section{Organograma}

O organograma da Supera veio se adequando conforme a empresa vinha evoluindo ao longo dos anos. Quando os irmãos Supera assumiram o negócio, assim como muitas empresas familiares, 
os dois gerenciavam praticamente tudo: Manoel mais focado nas áreas de produto e comercial e Joaquim, com foco maior nas áreas industrial, financeira e administrativa. À medida que a empresa crescia, novas atividades/pessoas foram incorporadas ao processo (Anexo 2). Os irmãos Supera acreditavam muito que a estratégia é que define a estrutura, ou seja, a estratégia vem antes da estrutura - algo bem controverso na época e que até hoje está presente nas discussões empresariais.

\section{Principais informações do negócio Faturamento}

A Supera teve, ao longo de sua trajetória, crescimentos expressivos de faturamento, especialmente até o ano de 2012. Os marcos estratégicos da empresa (quatro pilares) foram os grandes responsáveis por esses movimentos. Passados quase 20 anos da sua fundação, em 1990, a empresa fechou o ano com o faturamento de $\mathrm{R} \$ 40$ milhões - quatro vezes maior que o realizado no ano em que os irmãos Supera compraram a empresa do Tio Pereira. O faturamento da empresa evoluiu de maneira significativa a partir dos anos 1990, com a criação das duas gerências (produto e comercial). Foi um marco para a empresa, o primeiro passo para início do processo de profissionalização.

No ano de 2000, a empresa registrou o ápice de faturamento de seu segundo salto - reflexo da reestruturação (profissionalização) geral da empresa, especialmente na área de negócios. À medida que o portfólio aumentava, novos e maiores clientes foram incorporados à carteira da Supera. Em 10 anos, a empresa dobrou o faturamento.

A partir da estruturação das áreas-chave da empresa, especialmente da área comercial, o faturamento da um novo salto, chegando em 2010 ao valor de R \$ 120 milhões. Nesse momento, a Supera já atuava em todo o território nacional, presente nos maiores clientes de varejo exclusivamente supermercadistas. Parecia não haver mais espaço para crescimento na ordem de duas casas para a operação da Supera, pois o canal de varejo estava praticamente saturado. A empresa já estava presente nos principais clientes.

O questionamento nesse momento era: Como crescer? Essa questão foi respondida a partir da contratação de um Diretor Comercial. Esse profissional era oriundo de outro segmento, mas tinha ampla experiência no canal atacadista - em que, até então, a Supera não tinha atuação. Com isso, após essa contratação, dada a sua ampla rede de contatos no canal, a Supera começou a comercializar o seus produtos no atacado - que tem por característica principal a compra de grandes volumes. $\mathrm{O}$ que parecia uma grande incógnita em 2010, em pouco tempo, um ano depois, já estava materializado na abertura e consolidação de um novo canal.

Com a entrada no canal atacadista, a empresa mudou de patamar, alavancando o faturamento em 2011 para R 210 milhões (com crescimento de 75\% em relação ao ano de 2010), boa parte em função dos novos clientes atacadistas. Esse movimento continuou impactando de maneira significativa (crescimento de dois dígitos) o faturamento da empresa até 2012, quando a Supera fechou o ano com R\$ 310 milhões de faturamento anual. Nesse ano, a Supera havia conquistado o maior cliente atacadista do Brasil, chamado Atacado Mineirão.

Entretanto, nos três anos subsequentes, a Supera não teve o mesmo êxito dos anos anteriores, pois o seu faturamento permaneceu praticamente estabilizado nos patamares de 2012. O Anexo 3 demonstra a evolução do faturamento da Supera desde a sua fundação.

\section{Canal de distribuição}

A Supera atuou exclusivamente no varejo até o ano de 2010. A partir de 2011, a empresa passou a atuar no canal atacado. E já no primeiro ano, dada a expressividade dos clientes desse canal, ele passou a representar uma fatia importante do faturamento da empresa - 35\% das vendas totais. Como a empresa entendia que existia uma avenida grande de oportunidade nesse canal, direcionou 
todos os seus esforços para conquistar novos clientes. Com isso, em 2012, a participação do atacado passou para expressivos 50\% - ou seja, em dois anos de atuação nesse novo canal, ele já representava metade de todas as vendas realizadas pela Supera.

Nos anos subsequentes, a participação do canal atacado manteve-se em crescimento. Isso mudou totalmente a configuração da distribuição dos produtos da Supera no período de cinco anos (2010-2015). Como consequência, o canal atacado passou a ser a principal fonte geradora de receita da empresa, chegando a incríveis 70\% de participação em 2019 (Anexo 4). Com esse movimento, a configuração do faturamento entre as regionais também foi impactada, pois os maiores clientes atacadistas concentram-se na região Centro-Oeste $(\mathrm{CO})$ do País - especificamente no estado de Minas Gerais. A partir de 2012, a região CO passou a representar 55\% das vendas da empresa (Anexo 5). Com isso, o principal mercado da marca deixou de ser a região Sul - que saiu de $50 \%$ de participação em 2010 para $15 \%$ em 2015.

\section{Base de clientes}

A base de clientes da Supera foi aumentando gradativamente ao longo dos anos, chegando ao seu ápice ao final do ano de 2010, com 4.255 clientes. Até então, o crescimento da base, sustentado pela estratégia de expansão da empresa, seguia o ritmo do crescimento do faturamento. Entretanto, a partir do momento em que a Supera adotou a estratégia de direcionar os seus esforços para o canal atacadista, esse cenário mudou. Especialmente após a conquista do cliente Atacado Mineirão, a Supera começou a perder clientes - ano a ano.

Em cinco anos, a base de clientes reduziu-se em mais de 50\%, chegando ao final de 2015 a 2.109 clientes (Anexo 6). Isso se deu em função de a condição comercial do cliente Atacado Mineirão ser tão vantajosa a ponto de ele vender produtos da própria Supera mais barato do que a empresa vendia para os pequenos supermercados. Sendo mais claro, tamanho era o volume de compras desse cliente que ele acabou se tornando um "concorrente" da empresa com os seus próprios produtos.

Dessa forma, aquele cliente pequeno, que compra um volume baixo de produtos, não tem um desconto muito elevado e, consequentemente, não é vantajoso comprar direto da indústria. $\mathrm{O}$ reflexo desse processo de verticalização da venda pode ser observado na Evolução da participação dos clientes (Anexo 7). Em 2010, ano anterior à Supera começar a operar no canal atacado, a participação dos clientes de pequeno porte no faturamento da empresa representava $70 \%$ - ou seja, a distribuição da empresa era horizontalizada. A partir de 2011, o canal atacado começou a ser o protagonista, aumentando a sua participação, ano pós ano. Com destaque para a participação do cliente Atacado Mineirão, o faturamento da empresa cresceu de modo exponencial em cinco anos $15 \%$ (2012); 20\% (2013); 23\% (2014) e 30\% (2015).

\section{Portfólio de produtos}

O portfolio de produtos da Supera é composto por três categorias de produtos. A categoria 1 é a que tem maior representatividade $-70 \%$ do faturamento. O principal produto dessa categoria é o Superamax (Anexo 8). Esse produto foi lançado em 1983 e tornou-se líder de mercado em pouco mais de dois anos, devido a sua entrega de valor (especialmente, funcionalidade e design). A participação de mercado do Superamax é de $65 \%$ de share - o que o coloca na posição de referência da categoria. O produto ficou tão conhecido no mercado que virou sinônimo da categoria, ou seja, quando os clientes procuravam por essa categoria de produto, perguntavam: "Vocês tem o Superamax da empresa X?".

Esse posicionamento assegurava uma grande vantagem em relação aos seus concorrentes. A equipe de vendas da Supera sempre usava a estratégia de "venda casada", ou seja, para comprar o Superamax, os clientes precisavam comprar os demais produtos do portfólio da empresa. Foi dessa 
forma, inclusive, que a Supera conseguiu entrar no canal atacado. O produto era muito desejado pelos consumidores e, especialmente, pela equipe de vendas do atacado.

Além de ser o principal produto em termos de faturamento, o Superamax também era o produto com maior rentabilidade da empresa. Uma dupla rara de se encontrar - alto volume x alta rentabilidade. A margem bruta do Superamax chegou a incríveis 67\% em 2010. Isso garantiu à Supera muitos anos de excelentes resultados financeiros. Entretanto, a partir da entrada no canal atacado, esse cenário mudou. Como esse perfil de cliente tem como característica a compra de grandes volumes, o preço é um fator decisivo. Atraída pela oportunidade de vender grandes volumes, a Supera caiu em uma "armadilha". Cada vez ela dependia mais do atacado. E essa dependência fez com que o poder de barganha passasse para o lado do comprador - por consequência, preço baixo, margem baixa (Anexo 9).

\section{Informações de mercado}

O tamanho do mercado em que a Supera atua gira em torno de $\mathrm{R} \$ 800$ milhões por ano. Esse mercado possui vários segmentos de atuação: varejo alimentar (supermercados), com 55\% de share; varejo utilidades domésticas, com $35 \%$ de share, e demais canais ${ }^{1}$ com $15 \%$ de share (Anexo 10). $\mathrm{O}$ mercado cresce em torno de $5 \%$ a $7 \%$ ao ano (Anexo 11). O perfil do consumidor desse mercado é, em sua grande maioria, formado por mulheres (70\%) com entre 23 e 75 anos. A leitura de share é feita pela empresa de pesquisa Nielsen, a qual traz apenas $15 \%$ da fatia do mercado, já que ela audita somente grandes redes nacionais e regionais de varejo alimentar.

A Supera é líder no mercado nacional, com participação de $40 \%$ (share valor). Seus principais concorrentes, embora com uma fatia menor de mercado, têm uma posição geográfica mais privilegiada, considerando os maiores mercados de consumo no Brasil - o concorrente " $A$ " tem sede em SP (31\% de share valor) e o concorrente "B", no RJ (com 19\% de share valor). Portanto, as três empresas detêm, juntas, $90 \%$ do mercado - sendo que os demais $10 \%$ estão distribuídos entre pequenas empresas, com atuação regional (Anexo 12).

A Supera tem focado seus esforços em manter a hegemonia em relação aos seus concorrentes, mantendo seu posicionamento, que está sustentado em qualidade, design e funcionalidade dos produtos, algo que é reconhecido por clientes (varejistas) e consumidores finais. Entretanto, o processo de verticalização das vendas tem impactado de maneira negativa a imagem da empresa perante os varejistas, sobretudo os de médio e pequeno portes, uma vez que a relação com eles está estremecida, em função dos baixos preços praticados pelos atacados nos produtos da Supera.

\section{O que eu vou fazer para reverter essa situação?}

No outro dia, após a ligação do CEO, João chegou à empresa bem cedo. Convocou uma reunião com toda a equipe comercial, marketing e produto. João havia passado a noite em claro, pensando como abordaria o assunto com a equipe - dado que o contexto havia mudado, agora precisava apresentar um plano em 30 dias que contemplasse a virada do negócio em seis meses e não mais em 12 meses, conforme havia sido combinado em sua contratação.

João sabia que não seria tarefa fácil, mas, ao mesmo tempo, ele estava confiante, pois três meses já haviam se passado e João já tinha o diagnóstico detalhado da situação da empresa e um plano macro desenhando. Então, nesse momento, o grande desafio era acelerar a execução. Ele sabia que precisaria do empenho e dedicação de todos. Na reunião com a equipe, João procurou ser o mais transparente possível, deixou claras a urgência e gravidade da situação - mas não mencionou a questão final da ligação do CEO: "nossos empregos estão em jogo". João sempre procurava dosar o nível de pressão na equipe - nem muito, nem pouco; muitas coisas ele absorvia e não repassava.

\footnotetext{
${ }^{1}$ Casa de ferragens, material de construção, hotéis, pousadas, lojas de rede eletro e hospitais.
} 
O primeiro ponto definido na reunião com a equipe foi o cronograma de trabalho. João sempre foi muito organizado e sempre priorizou a entrega dos projetos de maneira antecipada. Dessa forma, mesmo com 30 dias para entregar o plano, João combinou com a equipe que eles entregariam em três semanas. Passado esse período, depois de muitas reuniões de alinhamento, o projeto estava pronto para ser apresentado na reunião do Conselho de Administração.

Era uma tarde de sexta-feira, ainda inverno, chuvosa e fria. João chegou uma hora antes para testar todos os equipamentos - ele sempre fazia isso. João sabia a importância daquela reunião, e nada poderia sair errado. Para garantir que todas as informações necessárias estariam disponíveis, João convidou os gerentes das áreas comercial. marketing e produto para participarem da reunião algo que nunca havia acontecido na empresa, pois os gerentes não participam das reuniões do Conselho, somente a diretoria. Além de garantir as informações, João tinha outros dois objetivos com esses convites: (1) mostrar ao Conselho que todos estravam envolvidos na construção do plano - para passar credibilidade, pois João estava havia apenas três meses na empresa; e (2) engajar a equipe no processo de execução, pois o que ficasse decidido nessa reunião teria que ser executado por todos.

João iniciou a reunião apresentando o diagnóstico que ele havia elaborado ao longo dos seus três meses de empresa. João havia percorrido boa parte do Brasil, visitando os clientes de todos os portes e canais de distribuição. Após 40 minutos de apresentação detalhada da situação da Supera no mercado, João finalizou a primeira parte da apresentação com um slide cujo título era "principais ofensores do resultado". O assunto era de conhecimento prévio, pois João havia circulado uma apresentação entre a diretoria e Conselho - com a intenção de facilitar a discussão na reunião do projeto.

João destacou que, ao longo dos últimos cinco anos, a dependência do canal atacadista tinha aumentado de maneira significativa, chegando aos atuais $70 \%$ - ou seja, de tudo que a Supera vende, $70 \%$ são destinados a esse canal. E com um grande agravante: essa venda tem uma grande concentração em um único cliente, que fica em MG, chamado Atacado Mineirão - por consequência, isso o torna o maior cliente da empresa.

Dessa forma, Superamax, o principal produto da empresa (considerado um produto "vaca leiteira" - Anexo 13), um produto líder de mercado, com 65\% de share valor na sua categoria, tem suas vendas concentradas, praticamente, em um único cliente no estado de MG - pois ele compra em torno de $90 \%$ da produção dessa linha de produto. Tal situação atribuiu a esse cliente um alto poder de barganha nas negociações com a empresa e, sobretudo, criou, ao longo dos anos, uma alta dependência de vendas - algo que coloca a empresa em desvantagem no processo de negociação. Esse contexto de concentração de vendas e baixo poder de barganha nas negociações com o maior cliente da empresa pressiona a margem dos produtos e, por consequência, afeta o EBITDA da empresa (Anexo 14).

Na sequência, conforme combinado com o CEO, João apresentou o plano para reverter a situação apresentada, ou seja, contemplando os principais ofensores do resultado. João também pretendia que os Conselheiros e o CEO contribuíssem com ideias, por esse motivo ele havia circulado o diagnóstico com antecedência. Tanto que, ao iniciar a apresentação dessa parte, ele começou dizendo:

- Dada a urgência e complexidade da situação, minha sugestão é que, após a minha apresentação, todos coloquem o seu ponto de vista e suas contribuições com base nas informações que circulei para toda a diretoria.

\section{Caminhos estratégicos}

João apresentou o plano que havia desenvolvido com a equipe e, na sequência, os Conselheiros e o CEO também apresentaram as suas contribuições. O primeiro tema abordado por 
João gerou bastante polêmica, logo no início - pois ele sugeriu que a Supera deveria parar de vender ao Atacado Mineirão imediatamente. João argumentou que o ponto central dos resultados decrescentes de rentabilidade do negócio decorria das negociações com esse cliente. Muito enfático, como sempre, João disse:

- Vamos quebrar se continuarmos neste ciclo vicioso.

Nesse momento, todos ficaram bem apreensivos na sala. Na sequência, Albuquerque, CEO da empresa, reforçou, usando algumas metáforas:

- Pessoal, o João tem razão, precisamos estancar o sangue, estamos sagrando no osso. Nosso principal produto (Superamax) está perdendo margem a cada ano, se continuarmos assim, vamos matar a "vaca leiteira" da Supera.

Nesse momento, um dos Conselheiros, que se chamava Arnaldo, fez uma colocação:

- Acho que parar de vender para o Atacado Mineirão vai afetar de forma significativa a nossa receita, vamos perder muito faturamento.

Em complemento, outro Conselheiro, chamado Antenor, se manifestou:

- Eu concordo com o Arnaldo, não podemos correr esse risco, ao mesmo tempo, acho que precisamos encontrar uma alternativa - ou seja, alguma estratégia mais rentável que faça com que não tenhamos uma redução brusca de orçamento. Estou falando de alternativas de negócios com volume, mas com rentabilidade.

João concordou com Arnaldo e Antenor:

- Sim, concordo com vocês, nosso plano está contemplando exatamente isso. Nossa proposta é desenvolver distribuidores regionais onde nossa marca terá uma representatividade maior. Precisamos de um parceiro que foque a venda de valor (qualidade, design e funcionalidade), não apenas preço, assim como o Atacado Mineirão. Podemos usar parte do desconto que concedemos hoje ao Mineirão para fazer campanhas com equipe de vendas do distribuidor e investir em materiais de ponto de venda (trade marketing). Para isso, precisamos parar de vender para $o$ Mineirão, pois, com o preço que ele pratica hoje, os distribuidores não teriam como competir.

Os Conselheiros ficaram pensativos por alguns instantes, e João continuou:

- Mais uma questão que gostaria de colocar, junto com esse plano de distribuidores regionais; nossa proposta é estruturar a área de produto usando o modelo de Gestão de Categoriaou seja, assim teríamos uma gerência focada na categoria 1, por consequência, dando uma atenção maior ao principal produto da empresa (Superamax).

Após a fala de João, novamente o silêncio tomou conta da sala. Todos estavam refletindo sobre os possíveis caminhos estratégicos. Foi então que o CEO questionou os Conselheiros:

- Vocês não acham que faz sentido o que o João nos apresentou?.

Todos fizeram um sinal de sim, mexendo as cabeças de maneira reflexiva. Diante daquela situação, com o aceno "positivo" do Conselho e o apoio do CEO, ele seguiu:

- Gostaria de trazer outras duas possibilidades que, na visão do time, vão nos ajudar nessa nova caminhada. A primeira sugestão é desenvolvermos uma segunda marca (do tipo "by Supera") para venda exclusiva no atacado. Com isso, evitamos o conflito de canais (varejo x atacado).

Mais um momento de silêncio na reunião. Os Conselheiros pareciam concordar com as proposições de João. Foi então que o terceiro Conselheiro, Antônio, se manifestou:

- Acho que pode ser um bom caminho, mas, até lançarmos essa marca, precisamos fazer um reajuste de preços significativo no Atacado Mineirão, especialmente no Superamax, chegando ao final de seis meses em $25 \%$ de incremento no mínimo.

Dessa vez, foi João que ficou pensativo. Ele acenou com a cabeça sem muita segurança (como quem diz: Sim, mas como vou fazer isso?). Mas, sem titubear, João disse:

- Acho que é possível, Antônio, pois minha segunda sugestão é abrirmos um Centro de Distribuição (CD) em SP, assim podemos ficar mais próximo dos grandes varejistas e, ao mesmo 
tempo, atuar de forma mais incisiva nos mercados de SP e RJ-maior potencial de consumo do Brasil.

Enquanto João continuava, o CEO interveio:

- Me parece uma excelente alternativa, pois, inclusive, pode viabilizar a abertura de outros canais de distribuição, como hotéis. disse:

Nesse momento, já haviam passado quatro horas de reunião, e o CEO retomou a palavra e

- Olha, acho que foram levantadas boas alternativas na nossa reunião. Acho que a discussão foi boa, todos contribuíram - era exatamente isso que esperávamos. Entretanto, ainda temos um longo caminho pela frente. A minha sugestão é que o João, juntamente com a equipe, aprofunde os temas abordados, ou seja, temos que pensar no "como". Junto com isso, traga outras alternativas que possam surgir, dado que a discussão foi muito boa.

Diante da fala do CEO, João disse:

- Certo, Albuquerque, vamos seguir dessa forma. Amanhã mesmo, vou dar continuidade ao trabalho juntamente com a equipe. Além disso, hoje ainda vamos circular um material com as principais ideias levantadas na reunião para termos o registro (Anexo 15).

Dito isso, a reunião foi encerrada. Na avaliação de João, a reunião foi positiva, embora a sua expectativa fosse sair com o plano aprovado, o que não aconteceu, pois o CEO sugeriu que as ideias fossem aprofundadas.

Dessa forma, o dilema do João ainda permanecia, pois não ficou decidido qual seria o melhor caminho, ou seja, João ainda estava em dúvida: "O que eu vou fazer para reverter essa situação?". 
FATURAMENTO ESTAGNADO E BAIXA RENTABILIDADE. E AGORA, COMO A SUPERA VAI VIRAR... Alexsander Canaparro, Kadígia Faccin, Diego Marconatto

\section{Anexo 1. Trajetória estratégica Supera}

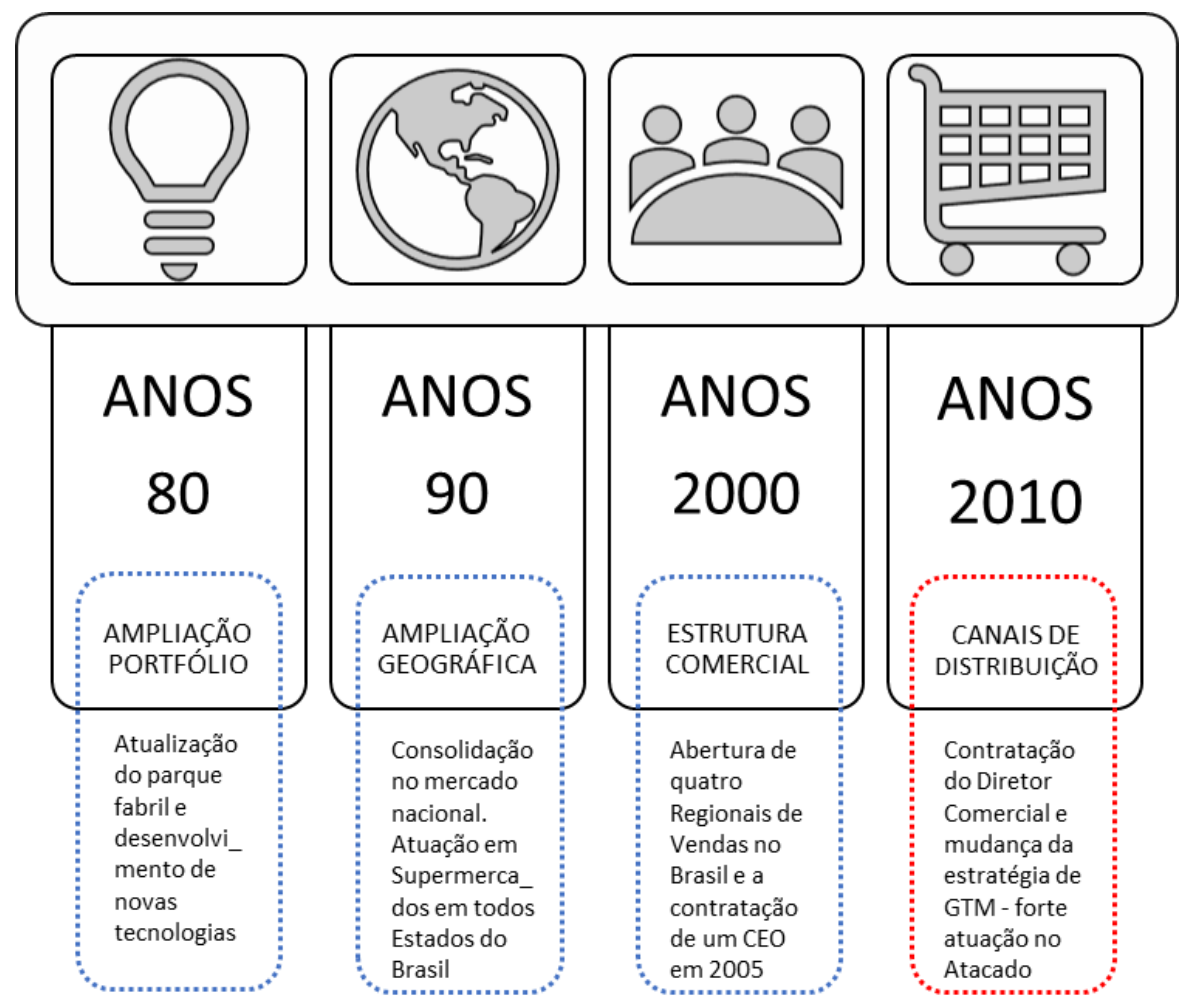


FATURAMENTO ESTAGNADO E BAIXA RENTABILIDADE. E AGORA, COMO A SUPERA VAI VIRAR... Alexsander Canaparro, Kadígia Faccin, Diego Marconatto

\section{Anexo 2. Evolução do organograma macro}
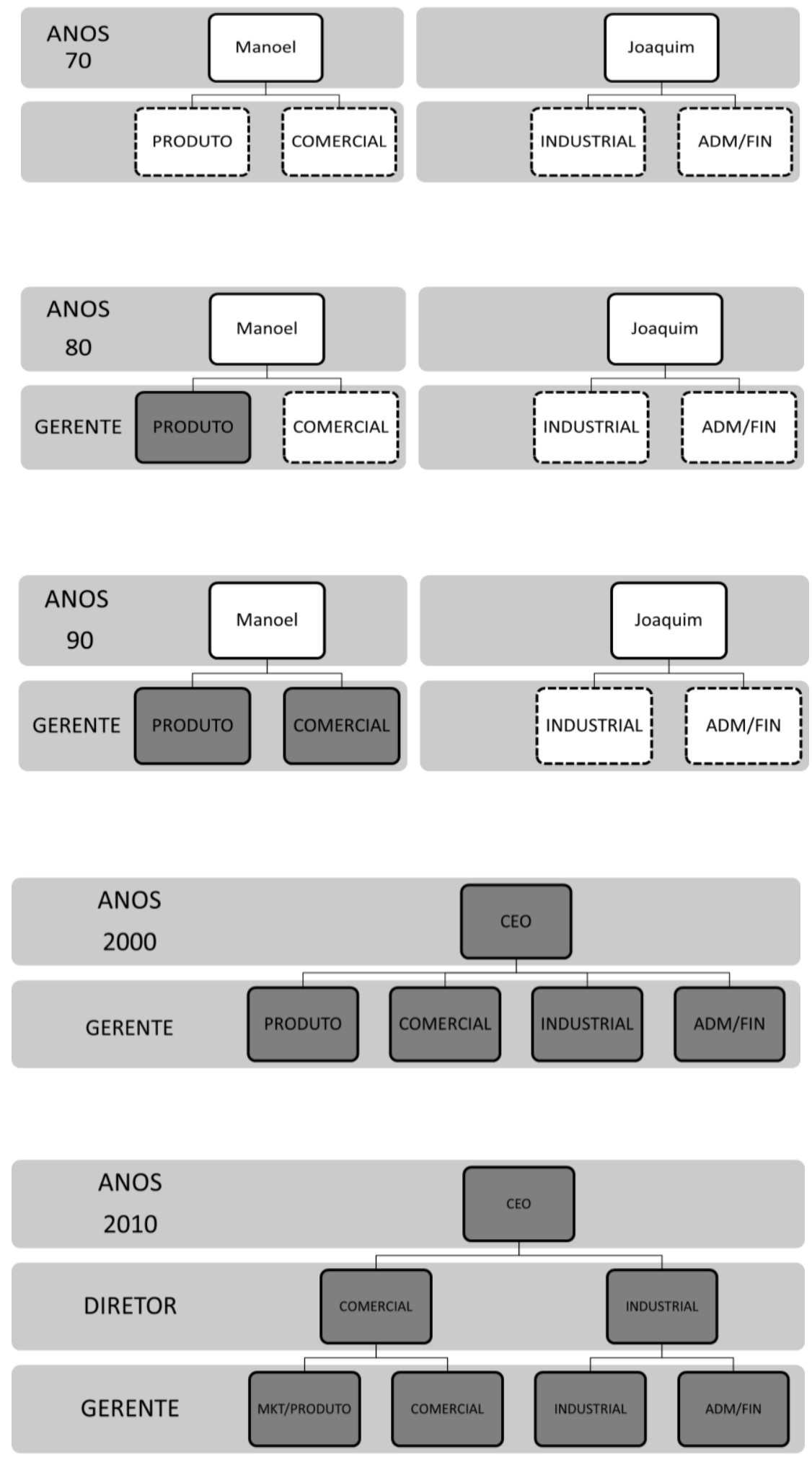
FATURAMENTO ESTAGNADO E BAIXA RENTABILIDADE. E AGORA, COMO A SUPERA VAI VIRAR... Alexsander Canaparro, Kadígia Faccin, Diego Marconatto

\section{Anexo 3. Evolução do faturamento}

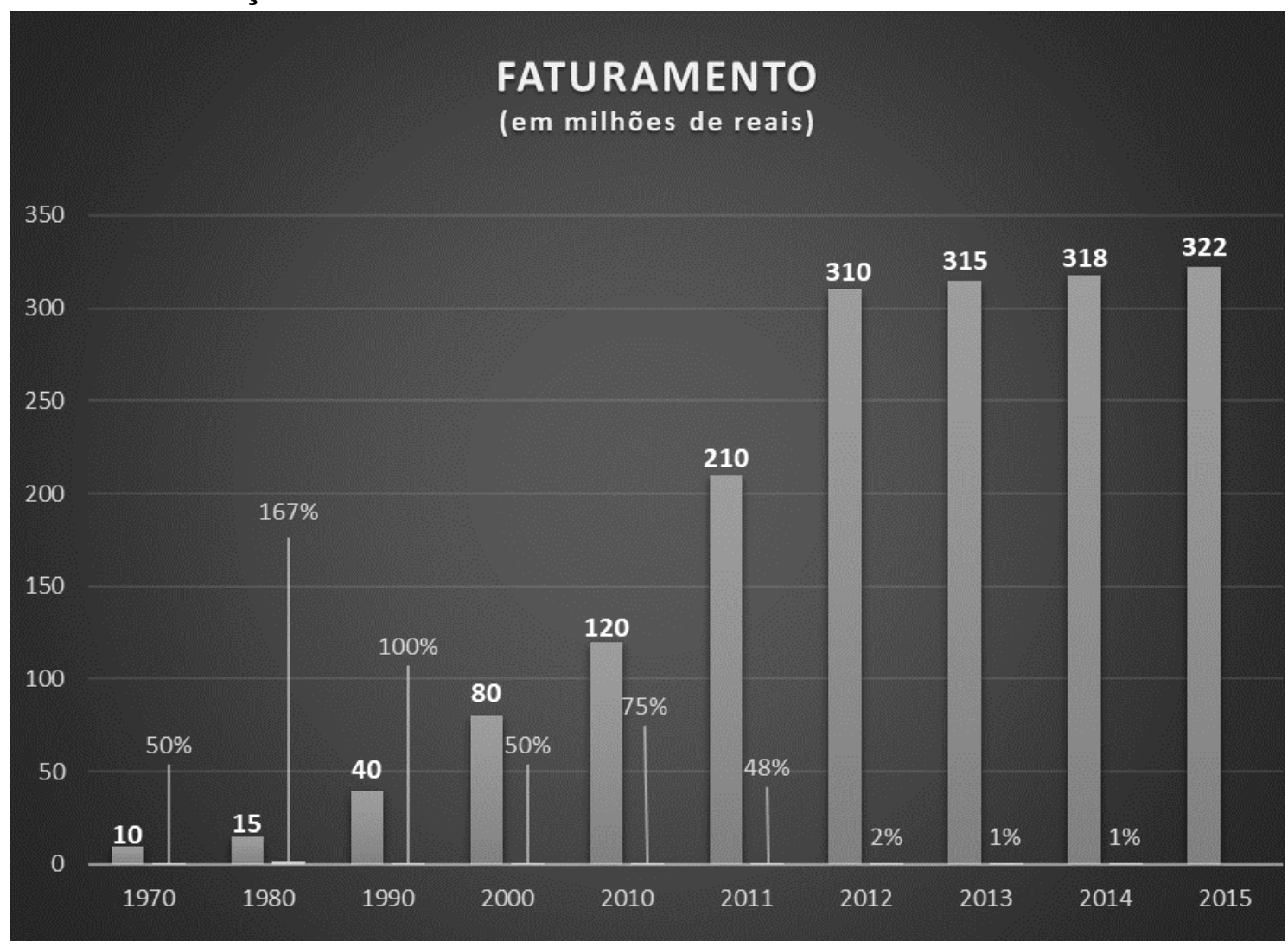

\section{Anexo 4. Participação dos canais no faturamento}

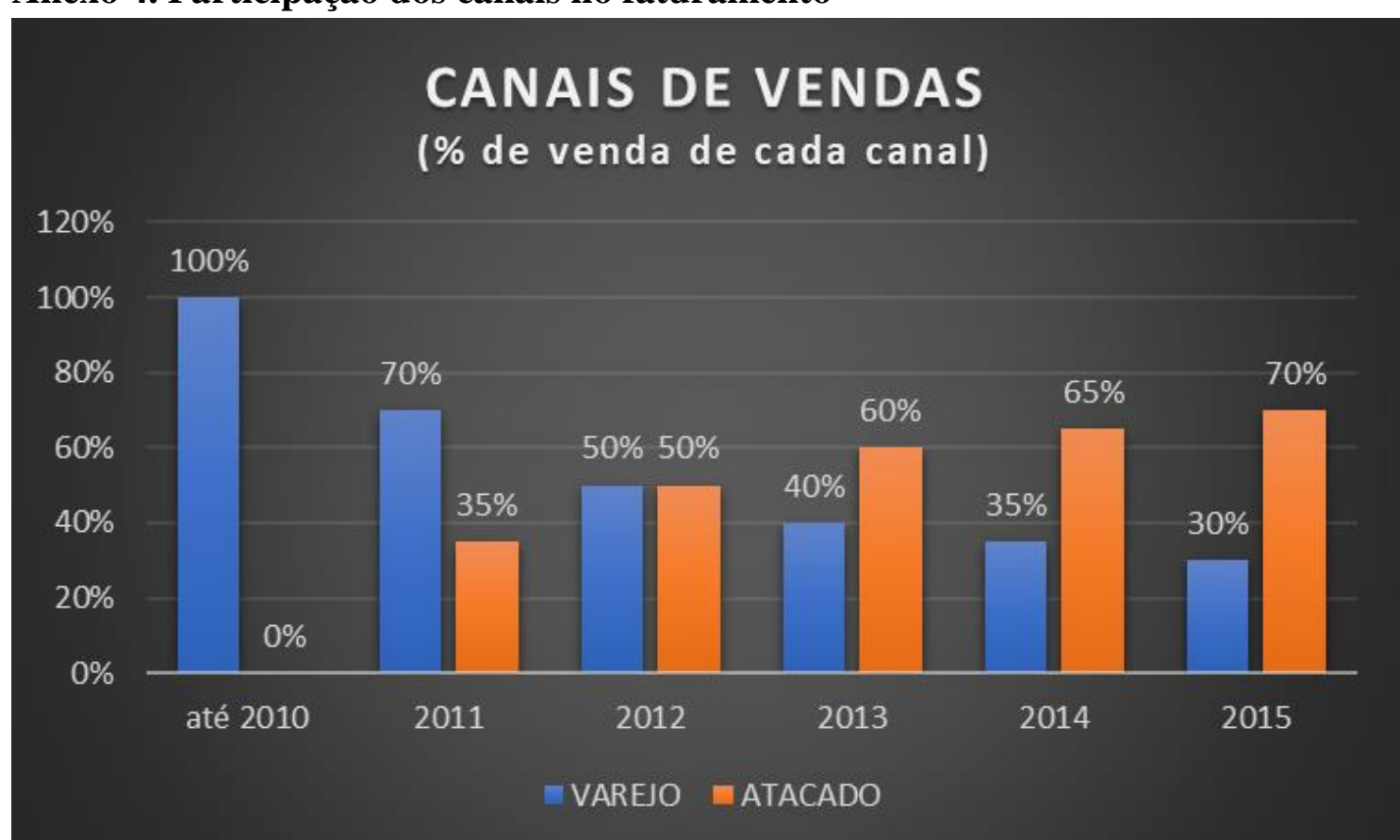


FATURAMENTO ESTAGNADO E BAIXA RENTABILIDADE. E AGORA, COMO A SUPERA VAI VIRAR... Alexsander Canaparro, Kadígia Faccin, Diego Marconatto

\section{Anexo 5. Participação das regionais}

\section{REGIONAIS DE VENDAS}

(\% de venda de por regional)

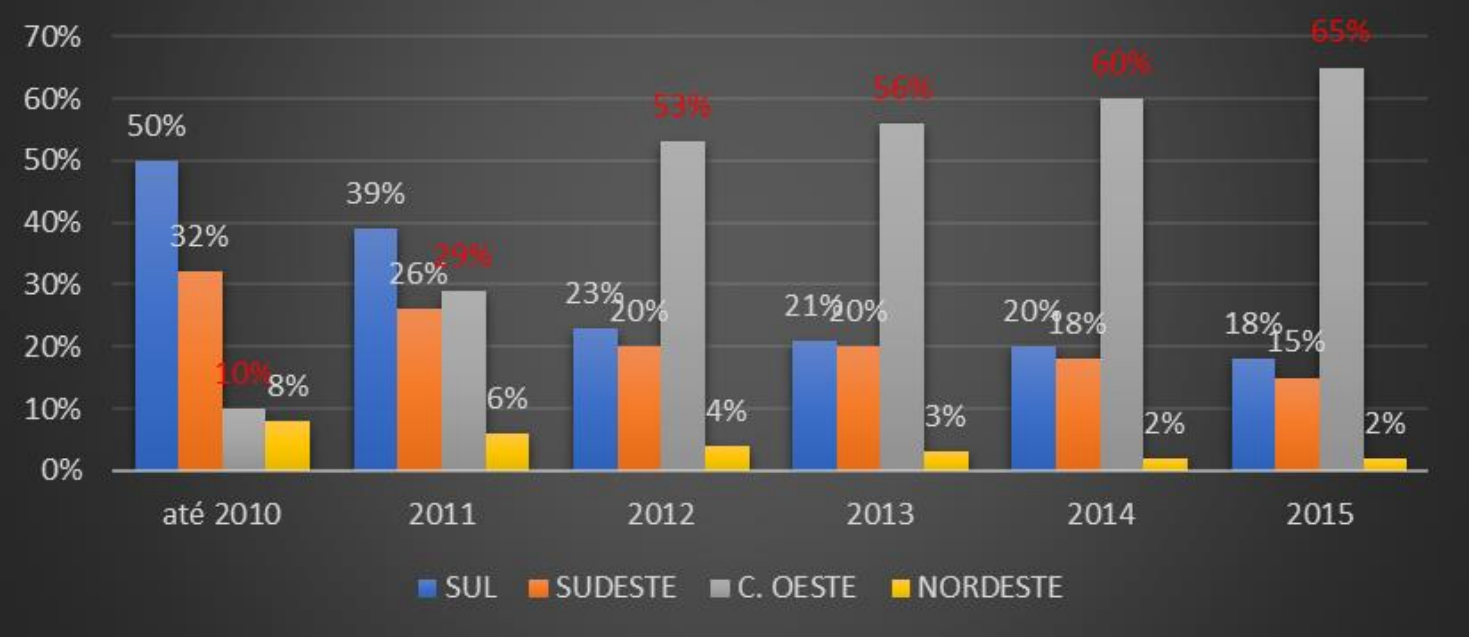

Anexo 6. Evolução da base de clientes

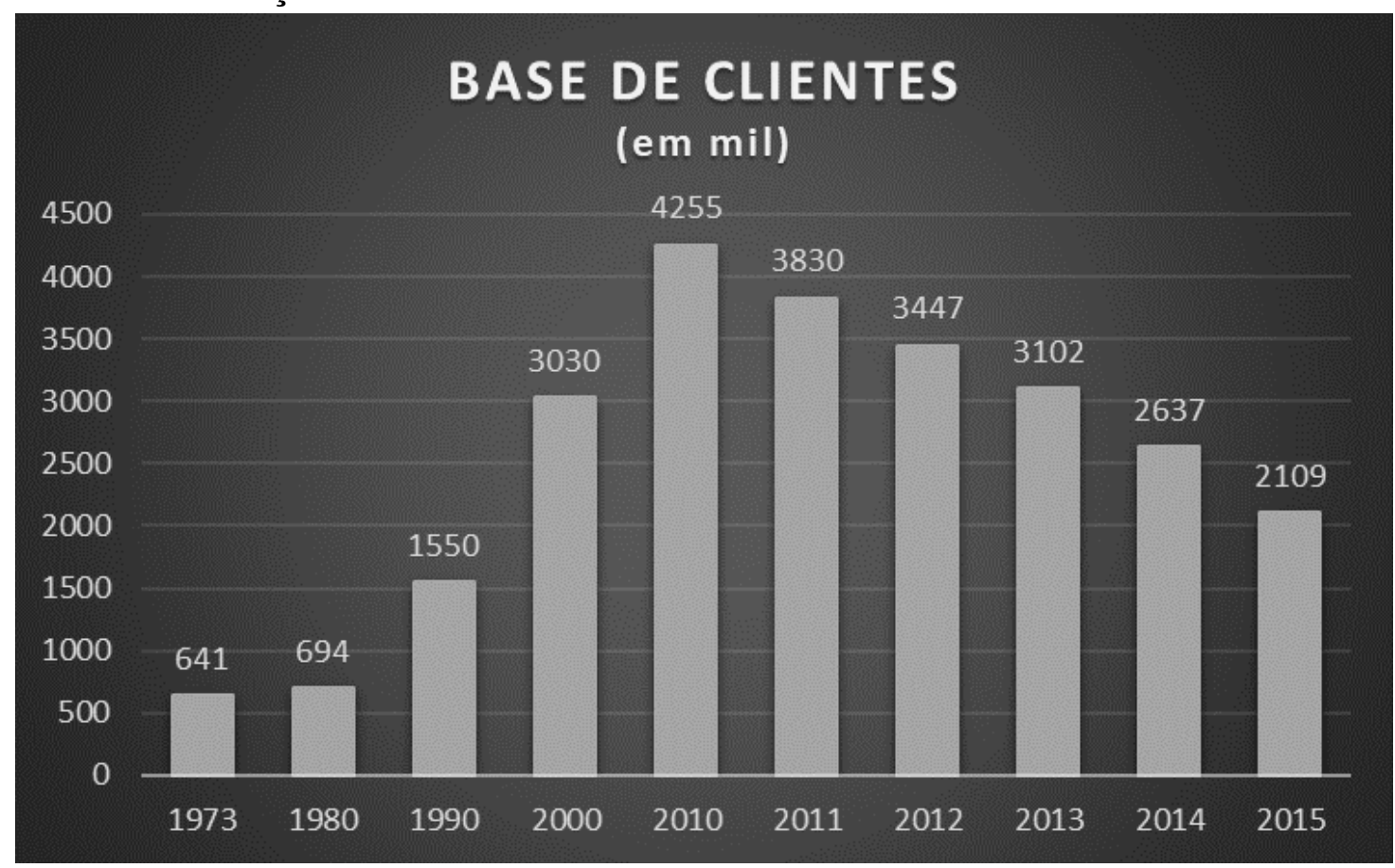


FATURAMENTO ESTAGNADO E BAIXA RENTABILIDADE. E AGORA, COMO A SUPERA VAI VIRAR... Alexsander Canaparro, Kadígia Faccin, Diego Marconatto

Anexo 7. Evolução da participação dos clientes/canais no faturamento anual

\begin{tabular}{|c|c|c|c|c|c|c|c|c|c|c|c|c|c|}
\hline \multirow{3}{*}{ CLIENTE } & \multicolumn{13}{|c|}{ EVOLUÇÃO DA PARTICIPAÇÃO DOS CLIENTES/CANAIS NO FATURAMENTO ANUAL } \\
\hline & \multirow{2}{*}{ CANAL } & \multicolumn{2}{|c|}{2010} & \multicolumn{2}{|c|}{2011} & \multicolumn{2}{|c|}{2012} & \multicolumn{2}{|c|}{2013} & \multicolumn{2}{|c|}{2014} & \multicolumn{2}{|c|}{2015} \\
\hline & & $\%$ & $\mathbf{R} \$$ & $\%$ & R\$ & $\%$ & $\mathbf{R} \$$ & $\%$ & $\mathbf{R} \$$ & $\%$ & $\mathbf{R S}$ & $\%$ & $\mathbf{R} \mathbf{S}$ \\
\hline Supermercado A & Varejo & $8 \%$ & 9,6 & $8 \%$ & 16,8 & $12 \%$ & 37,2 & $10 \%$ & 31,5 & $8 \%$ & 25,4 & $7 \%$ & 22,5 \\
\hline Supermercado B & Varejo & $6 \%$ & 7,2 & $6 \%$ & 12,6 & $9 \%$ & 27,9 & $8 \%$ & 25,2 & $7 \%$ & 22,3 & $6 \%$ & 19,3 \\
\hline Supermercado C & Varejo & $4 \%$ & 4,8 & $4 \%$ & 8,4 & $8 \%$ & 24,8 & $6 \%$ & 18,9 & $6 \%$ & 19,1 & $5 \%$ & 16,1 \\
\hline Supermercado D & Varejo & $4 \%$ & 4,8 & $4 \%$ & 8,4 & $3 \%$ & 9,3 & $2 \%$ & 6,3 & $3 \%$ & 9,5 & $3 \%$ & 9,7 \\
\hline Supermercado E & Varejo & $3 \%$ & 3,6 & $3 \%$ & 6,3 & $2 \%$ & 6,2 & $1 \%$ & 3,2 & $1 \%$ & 3,2 & $2 \%$ & 6,4 \\
\hline Supermercado F & Varejo & $2 \%$ & 2,4 & $2 \%$ & 4,2 & $2 \%$ & 6,2 & $2 \%$ & 6,3 & $2 \%$ & 6,4 & $2 \%$ & 6,4 \\
\hline Supermercado G & Varejo & $2 \%$ & 2,4 & $2 \%$ & 4,2 & $1 \%$ & 3,1 & $1 \%$ & 3,2 & $1 \%$ & 3,2 & $1 \%$ & 3,2 \\
\hline Supermercado H & Varejo & $1 \%$ & 1,2 & $1 \%$ & 2,1 & $1 \%$ & 3,1 & $1 \%$ & 3,2 & $1 \%$ & 3,2 & $1 \%$ & 3,2 \\
\hline Atacado A & Atacado & $0 \%$ & 0,0 & $10 \%$ & 21,0 & $10 \%$ & 31,0 & $11 \%$ & 34,7 & $12 \%$ & 38,2 & $10 \%$ & 32,2 \\
\hline Atacado B & Atacado & $0 \%$ & 0,0 & $8 \%$ & 16,8 & $8 \%$ & 24,8 & $9 \%$ & 28,4 & $10 \%$ & 31,8 & $9 \%$ & 29,0 \\
\hline Atacado C & Atacado & $0 \%$ & 0,0 & $8 \%$ & 16,8 & $8 \%$ & 24,8 & $9 \%$ & 28,4 & $9 \%$ & 28,6 & $10 \%$ & 32,2 \\
\hline Atacado D & Atacado & $0 \%$ & 0,0 & $6 \%$ & 12,6 & $6 \%$ & 18,6 & $7 \%$ & 22,1 & $7 \%$ & 22,3 & $7 \%$ & 22,5 \\
\hline Atacado $\mathrm{E}$ & Atacado & $0 \%$ & 0,0 & $3 \%$ & 6,3 & $3 \%$ & 9,3 & $4 \%$ & 12,6 & $4 \%$ & 12,7 & $4 \%$ & 12,9 \\
\hline Atacado Mineirão & Atacado & $0 \%$ & 0,0 & $0 \%$ & 0,0 & $15 \%$ & 46,5 & $20 \%$ & 63,0 & $23 \%$ & 73,1 & $30 \%$ & 96,6 \\
\hline Demais clientes & Varejo & $70 \%$ & 84,0 & $35 \%$ & 73,5 & $12 \%$ & 37,2 & $9 \%$ & 28,4 & $6 \%$ & 19,1 & $3 \%$ & 9,7 \\
\hline
\end{tabular}

Anexo 8. Participação categoria/produto no faturamento anual

\begin{tabular}{|c|c|c|c|c|c|}
\hline \multicolumn{6}{|c|}{ \% FATURAMENTO } \\
\hline CATEGORIA 1 & $70 \%$ & CATEGORIA 2 & $18 \%$ & CATEGORIA 3 & $12 \%$ \\
\hline Superamax & $50 \%$ & Produto A & $5 \%$ & Produto A & $3 \%$ \\
\hline Produto B & $5 \%$ & Produto B & $2 \%$ & Produto B & $2 \%$ \\
\hline Produto C & $3 \%$ & Produto C & $2 \%$ & Produto C & $2 \%$ \\
\hline Produto D & $2 \%$ & Produto D & $1 \%$ & Produto D & $1 \%$ \\
\hline Demais produtos & $10 \%$ & Demais produtos & $8 \%$ & Demais produtos & $4 \%$ \\
\hline
\end{tabular}

Anexo 9. Margem bruta do produto Superamax

\begin{tabular}{|c|c|c|c|c|c|}
\hline \multicolumn{5}{|c|}{ MARGEM BRUTA - SUEPERAMAX } \\
\hline 2010 & 2011 & 2012 & 2013 & 2014 & 2015 \\
\hline $67 \%$ & $55 \%$ & $40 \%$ & $30 \%$ & $25 \%$ & $25 \%$ \\
\hline
\end{tabular}


FATURAMENTO ESTAGNADO E BAIXA RENTABILIDADE. E AGORA, COMO A SUPERA VAI VIRAR... Alexsander Canaparro, Kadígia Faccin, Diego Marconatto

\section{Anexo 10. Segmentação de mercado}

\section{SEGMENTAÇÃO DO MERCADO}

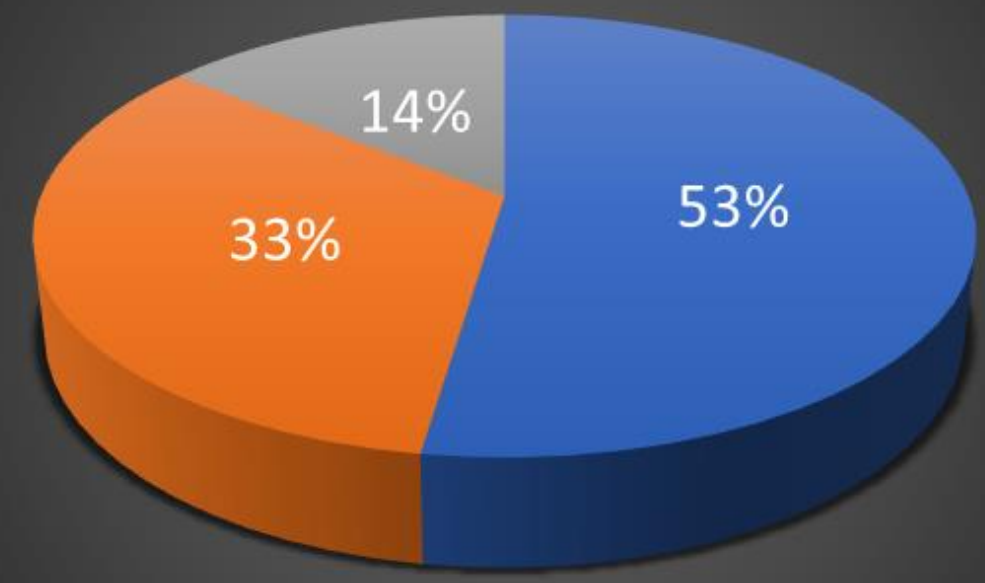

Anexo 11. Porcentagem de crescimento do mercado (anual)

\section{EVOLUÇÃO DO MERCADO}

( $\%$ de anual de crescimento)

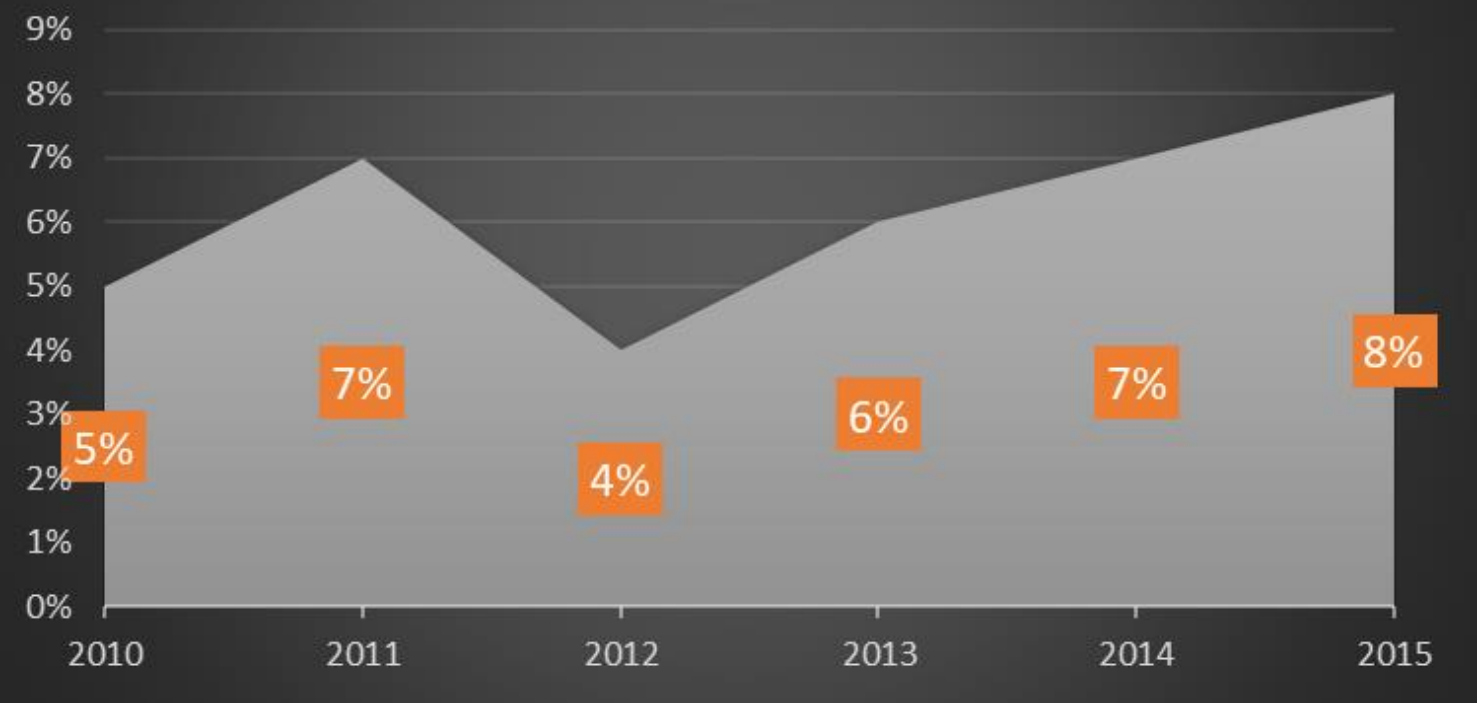


FATURAMENTO ESTAGNADO E BAIXA RENTABILIDADE. E AGORA, COMO A SUPERA VAI VIRAR... Alexsander Canaparro, Kadígia Faccin, Diego Marconatto

\section{Anexo 12. Participação de mercado da Supera}

\section{PARTICIPAÇÃO DE MERCADO}

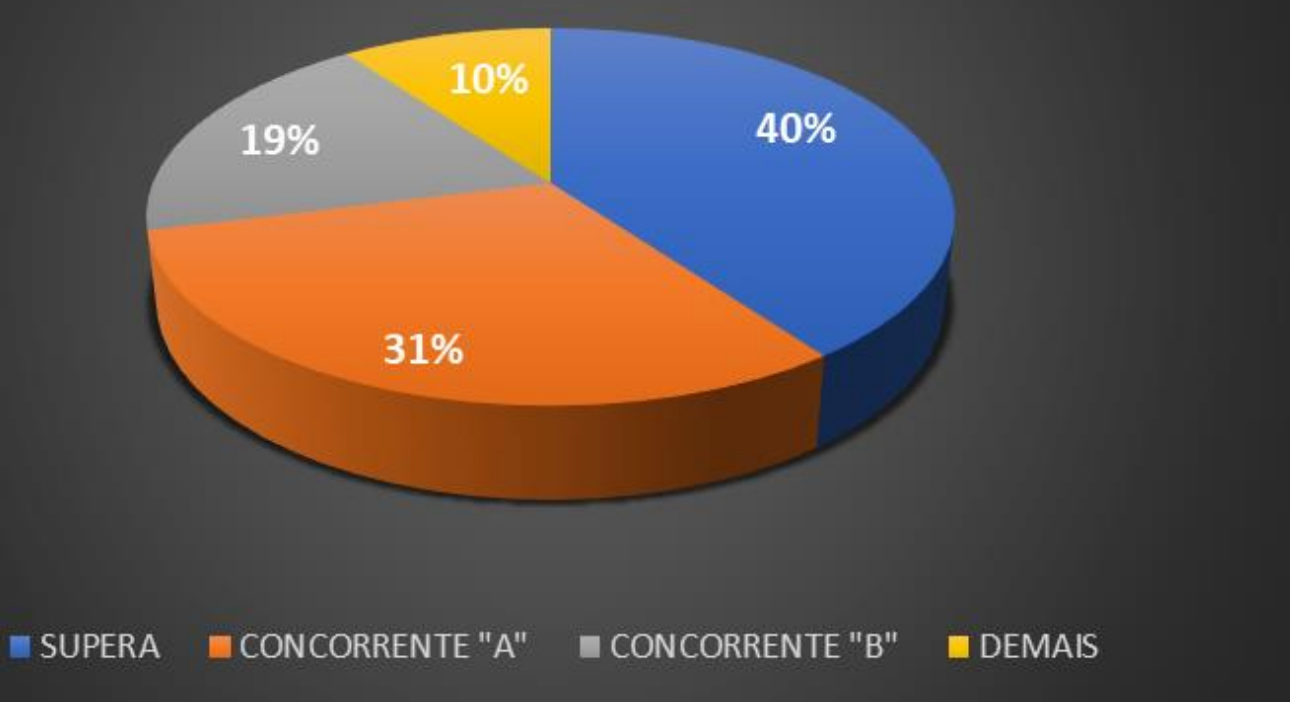

Anexo 13. Matriz BCG

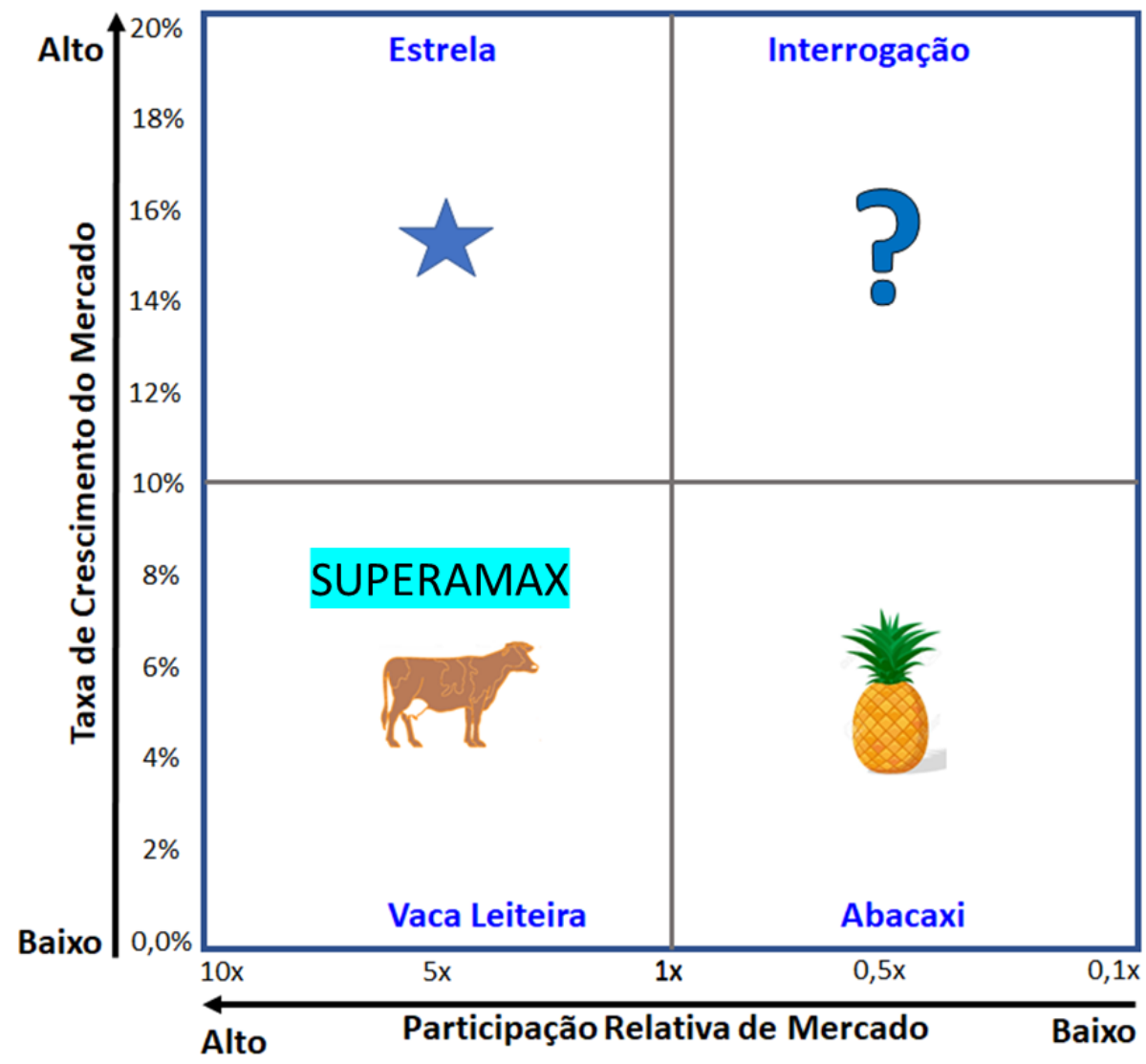


FATURAMENTO ESTAGNADO E BAIXA RENTABILIDADE. E AGORA, COMO A SUPERA VAI VIRAR... Alexsander Canaparro, Kadígia Faccin, Diego Marconatto

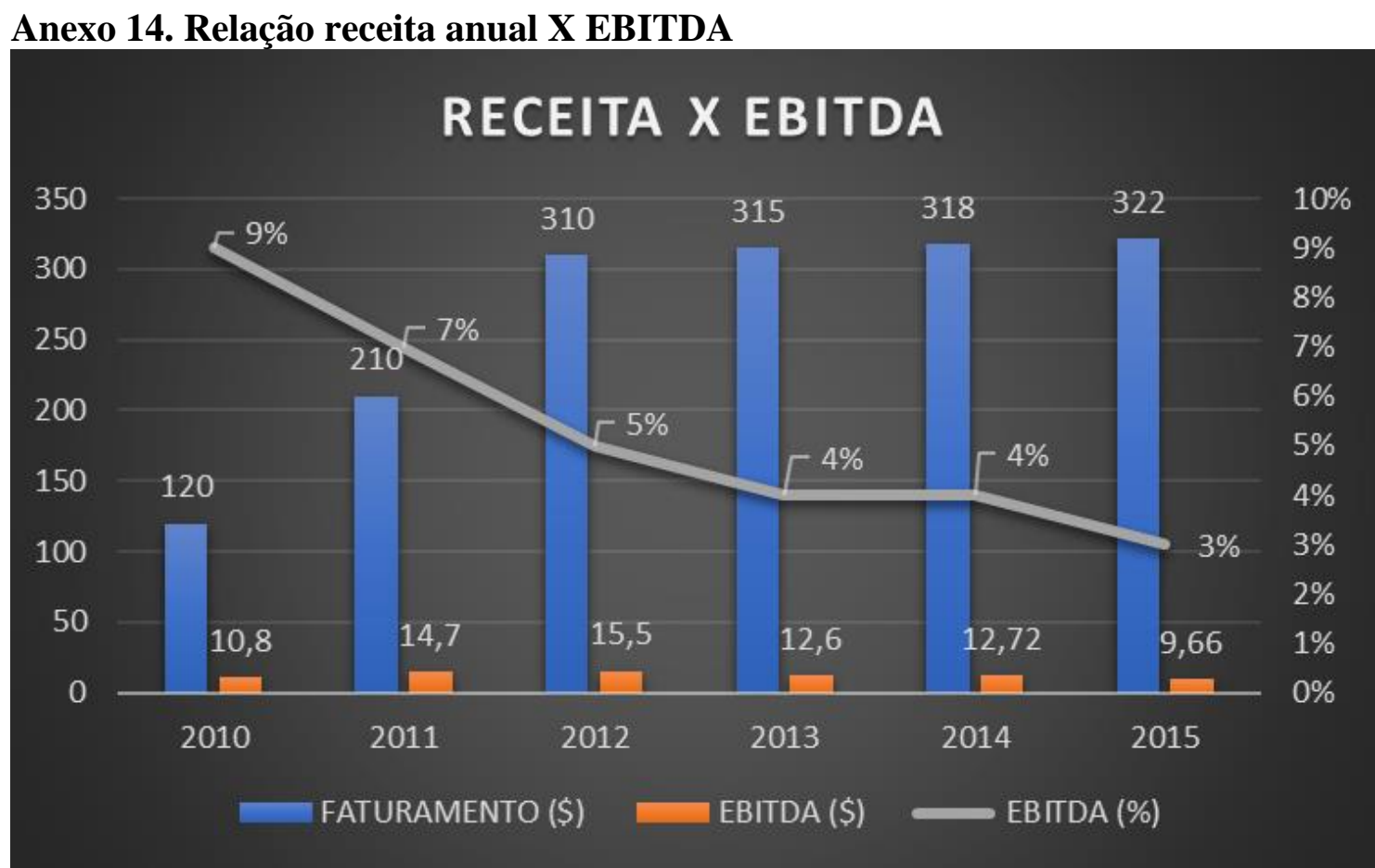

Anexo 15. Possíveis caminhos estratégicos

\begin{tabular}{|c|l|}
\hline \multicolumn{1}{|c|}{ POSSÍVEIS CAMINHOS ESTRATÉGICOS ABORDADOS NA REUNIÃO } \\
\hline \multicolumn{1}{|c|}{ Plano do João (equipe) } \\
\hline 1 & Parar imediatamente de vender para o cliente Atacado Mineirão \\
\hline 2 & Desenvolver distribuidores regionais \\
\hline 3 & Criar uma estrutura de gestão de categoria \\
\hline 4 & Desenvolver uma linha paralela de produtos exclusiva para o Atacado (segunda marca) \\
\hline 5 & Abrir um Centro de Distribuição (CD) em SP \\
\hline \multicolumn{1}{|c|}{ Conselheiros } \\
\hline 6 & $\begin{array}{l}\text { Acreditam que a Supera não pode deixar de vender para o Atacado Mineirão, pois isso iria } \\
\text { afetar o faturamento de forma significativa. }\end{array}$ \\
\hline 7 & Negociar nos próximos pedidos do Atacado Mineirão um aumento escalonado de preço. \\
\hline \multicolumn{2}{|c|}{ CEO } \\
\hline 8 & $\begin{array}{l}\text { Acredita que a Supera tem que buscar desenvolver outros canais de distribuição para } \\
\text { diminuir a dependência do atacado. }\end{array}$ \\
\hline
\end{tabular}

